\title{
ALGUNAS REFLEXIONES EN TORNO AL FIN DE LA HISTORIA A PARTIR DE LA EDAD MEDIA ${ }^{1}$
}

\section{SOME REFLECTIONS ABOUT THE END OF HISTORY FROM THE MIDDLE AGES}

\author{
ISRAEL SANMARTÍN ${ }^{2}$ \\ Investigador postdoctoral EHESS (París, Francia)
}

\begin{abstract}
Resumen
En el presente trabajo se estudia la idea de fin de la Historia tomando como eje la Edad Media. A partir de las reflexiones sobre acontecimientos, pensamiento y representaciones populares en el medievo, se estudiará su comparación con la época contemporánea y sus propios fines de la historia y con las concepciones teleológicas postocoloniales latinoamericanas, que se sitúan temporalmente entre los fines de la historia medievales y contemporáneos.
\end{abstract}

\section{Palabras clave}

Fin de la historia, milenarismo, historia del presente, apocaliptismo, San Agustín, Joaquín de Fiore, Walter Mignolo, postcolonialismo, teleología.

\begin{abstract}
The article studies the idea of end of History taking like axis the Moyen Age. The work compares the reflections on events, thought and representations populars in medievo, contemporary age and latinoamerican postocolonial studies, for searching the points of contact and differences between them.
\end{abstract}

\section{Keywords}

End of history, millenarism, contemporary history, apocaliptism, San Agustín, Joaquín de Fiore, Walter Mignolo, poscolonialism, teleology.

1 Entregado el 15.013.2009.

2 Este trabajo está desarrollado en el marco de la beca postdoctoral del Ministerio de Educación y Ciencia del gobierno de España que estoy desenvolviendo en la EHESS (París, Francia) en el grupo GAHOM bajo la dirección de Jérôme Baschet. 
El estudio de los fines de la historia en la Edad Media tienen una repercusión importante en el estudio de los fines de la historia contemporáneos, puesto que contienen ingredientes que podrían servir para localizar y estudiar la genealogía de ciertos conceptos presentes en todos los fines de la historia a lo largo de las diferentes épocas. De tal forma, la teleología, la escatología, la idea de una historia progresiva, etc. son fundamentales en este sentido. Abundando en estas cuestiones, tampoco es un secreto que la asociación de los fines de la historia es, en cierta medida, una reflexión sobre la eternidad del propio tiempo vivido y acontecido (la búsqueda del ideal perfecto de vida a través de una proyección ahistórica del presente donde se organizaría el tiempo en base aun futuro ideal vinculado al juicio final), vinculado, además, con el fin de siglo, sobre todo en lo relativo al año mil, que conlleva toda una serie de cuestiones relativas a la historia de las mentalidades y de las representaciones, como miedos, profecías, etc.

\section{EL FIN DE LA HISTORIA EN EL TIEMPO DE LA EDAD MEDIA}

En la Edad Media existieron diferentes formas de representación de los llamados "fines de la historia" que se proyectan en una reflexión sobre la utilización que hicieron los historiadores medievales sobre la "historia de su tiempo", que es un rasgo constitutivo de la historiografia desde sus orígenes, cuestión en la que interviene su carácter de materia "pública", es decir, su capacidad para establecer o narrar memorias públicas del pasado, y sobre todo del pasado reciente ${ }^{3}$. En tal sentido, el sentido existencial del tiempo es un elemento de la historiografía que no se deja amoldar simplemente por el mero "uso público" que se pueda hacer del pasado en un momento determinado, del mismo modo que los usos públicos del pasado tampoco se reducen únicamente a la memoria social. El problema de en qué medida las estructuras de la historiografía reflejan el tiempo de las sociedades a las que pertenece es un tema a debate en las últimas décadas. Sólo cuando el "presente estacionario" ha dejado de ser el eje de la narración histórica, es cuando ha podido abrirse camino la moderna disciplina histórica con su división de la historia en épocas y una metodología que ha acabado por conceder importancia a los acontecimientos cercanos considerados en sí mismos. Factores internos a la propia historia, cambios en la percepción del tiempo y nuevos retos del uso público del pasado

\footnotetext{
3 Pasamar Alzuria, G., Formas tradicionales y formas modernas de la "Historia del Presente". Historia social, $\mathrm{N}^{\circ}$ 62, 2008, pp. 147-169
} 
se han concretado como elementos base para el debate historiográfico hasta la actualidad $^{4}$.

En el sentido de lo apuntado, se puede decir que la historiografía medieval concedió importancia destacada a los hechos cercanos ${ }^{5}$, los correspondientes a la generación del autor o la inmediatamente precedentes, tal es el caso de autores cristianos desde Hidacio y las Etimologías de San Isidoro de Sevilla hasta los Anales de Zurita, aunque tampoco nos podemos olvidar de autores pertenecientes a lo que se denomina en la actualidad Francia, como Raoul Glaber o algunos autores musulmanes como Ibn Jaldún (siglo XIV) o las Memorias de Abdallah (siglo XI) ${ }^{6}$.

\subsection{Algunas representaciones del fin e la Historia en la Edad Media}

La cuestión de los fines de la historia relativa al milenarismo, apocaliptismo y fin del mundo ha enfrentado a distintos investigadores en los últimos años, sobre todo en Francia (Landes, Barthélémy, Gouguenheim, Lobrichon, etc.). En este sentido, podemos poner como ejemplo que el milenarismo significó dos cosas: una creencia de esperanza basada en unos versículos del capítulo 20 del Apocalipsis de San Juan donde dice que antes del juicio final reinará Jesucristo en un reinado de justicia y amor durante mil años ${ }^{7}$, pero también es la creencia de temor, de miedo, de acabamiento del mundo en el año mil ${ }^{8}$.

En el siglo X la perspectiva de la llegada del anticristo incitaba a interpretar las catástrofes naturales, epidemias y desórdenes de larga duración, originadas por la guerra, e igualmente las situaciones sociales o religiosas intolerables. Así, en la primera mitad del siglo X el abad Odón de Cluny estaba convencido de la llegada del anticristo y el fin del mundo, dada la oleada de injusticias. Aunque en el año 1000 no hubo psicosis (según algunos autores) ${ }^{9}$, sí había cierto temor a ver culminado el milenio durante el cual Satán estaba encadenado según el Apocalipsis ${ }^{10}$. Se puede

\footnotetext{
${ }^{4}$ Ver Guenée, Bernard, Le Métier d'historien au Moyen Age : etudes sur l'historiographie medievale, Paris, La Sorbonne, 1977

5 Gonzalo Pasamar ha denominado a estas formas de representación del tiempo en la Edad Media como "formas tradicionales de la historia del presente". Ver Pasamar Alzuria, G., Formas tradicionales y formas modernas de la "Historia del Presente", Historia social, № 62, 2008, pp. 147-169

6 Ver Orcástegui Gros, Carmen, La historia en la Edad Media : historiografía e historiadores en Europa Occidental, siglos V-XIII, Madrid, Cátedra, 1991

7 Ver De la Iglesia Duarte, José I., Milenarismos y milenaristas en la Europa medieval, IER, Logroño, 1999.

8 Pierre Bonassie et Pierre Toubert (ed)., Hommes et societés sans l'Europe de l'An mil, Press Universitarires du Mirail, Toulousse, 2004

9 Gouguenheim, Sylvain, Les Fausses Terreurs de l'an mil, Paris, Picard, 1999

${ }^{10}$ Ver Vaca Lorenzo, Ángel, En pos del tercer milenio. Apocalíptica, mesianismo, milenarismo e historia, EH, 2000
} 
descubrir cierto presentimiento del fin del mundo entre los participantes en ese fenómeno que fueron las cruzadas populares, especialmente durante la Primera Cruzada o las consignas de Bernardo de Claraval a comienzos de la Segunda Cruzada $^{11}$.

Por otro lado, en la misma época, el conflicto entre el papado y el imperio a propósito de la "querella de las investiduras" dio lugar a interpretaciones escatológicas. En el mismo sentido, el milenarismo actuó como una memoria colectiva en Francia que permitió en 987 a Hugo Capeto desbancar a los carolingios o ayudó en Alemania con Otón III a reivindicarse como fundador de un espacio político. La memoria colectiva es utilizada para convertir su memoria en memoria del conjunto social y a actuar de una forma que sólo parcialmente podemos estimar como inconsciente. Desarrolla un proceso de constante selección del material histórico que trata de combinar solidaridad y movilización de la comunidad. Como hemos dicho, algunos medievalistas han negado la existencia de esos terrores (Marc Bloch, Henri Focillon, Edmond Pognon, Gerges Duby) ${ }^{12}$, pero estas ideas tuvieron más difusión entre 940-970 y 1040-60 que en el año $1000^{13}$.

Por otro lado están las herejías y los movimientos de masas vinculadas a la época gregoriana, a la reforma religiosa y política eclesiástica, al maniqueísmo, etc. Estas herejías tenían una fuerte componente milenarista, profético, mesiánico: la esperanza en un mundo mejor. Esa esperanza reverdeció cuando había mayor desorganización social provocada por las rápidas transformaciones sociales y las normas persistentes de interacción social (cruzadas, etc.). Desde el XIII hay aparición de movimientos heréticos: en 1210 en Paris un grupo de eclesiásticos Amaury de Bène bajo la influencia de Joaquín de Fiore; también están los frailes apostólicos en 1260 en Parma; en el sur de Francia los beguinos; los movimiento de disciplinantes o flagelantes en la gran peste de 1349 en Alemania, Países Bajos y Flandes; los husitas en Bohemia en 1419, etc ${ }^{14}$.

A lo largo de la Edad Media la teología constituyó el marco fundamental para el desarrollo del pensamiento, no sólo referido a Dios y al mundo sobrenatural, sino a los propios mundos físico, social político y jurídico. Por esta razón, a la hora de plantearse el problema de la legitimidad de los movimientos de rebelión (de masas e intelectuales) contra el orden feudal (eclesiástico y señorial), fue fundamental el

11 Ver Rucquoi, Adeline, "El fin del milenarismo en la España de los siglos X y XI", en José I.

De la Iglesia Duarte, Milenarismos y milenaristas en la Europa medieval, IER, Logroño, 1999.

12 Ver, por ejemplo, Duby, Georges, L'an mil, Paris, Gallimard, 1980

13 Barthélemy, Dominique, La mutation de l’an mil a-t-elle eu lieu?, Fayard, París, 1997

14 Cohn, Norman, Les Fanatiques de l'Apocalypse, Paris, Payot, 1983 
desarrollo de los planteamientos teológicos, tanto por parte de los líderes religiosos de esos movimientos, que podían buscar en el Antiguo o el Nuevo Testamento las bases para su crítica del poder político o económico, como por parte de aquellos: teólogos, jueces..., que se encargaron de su represión. Por ejemplo, el anticristo ya está en la primera epístola de San Juan que decía que el Anticristo vendrá antes del Juicio Final. Las ideas medievales sobre el fin del mundo y del anticristo también recibieron la influencia de Remigio de Auxerre, que redactó a mediados del siglo IX comentarios sobre la segunda epístola de San Pablo a los Tesalonicenses y sobre el Apocalipsis, etc.

En el pensamiento medieval se partió de que existía una clara correspondencia entre el orden teológico, la estructura del mundo físico y los órdenes político, económico y jurídico. Dios, como creador del mundo, es el garante del orden físico y social del mismo, y por esta razón se interpretaba que rebelarse contra el poder eclesiástico, o contra el poder civil, era asimismo rebelarse contra Dios, razón por la cual, a partir de fines del Mundo Antiguo, y durante toda la Edad Media, la Iglesia apeló al brazo secular para reprimir la disidencia teológica, que, en muchos casos, podía servir de expresión de movimientos de protesta de tipo económico y social.

En torno al año mil se propaga la idea del Apocalipsis especialmente entre los monjes. Los autores eclesiásticos ven en la descripción de los pecados y los horrores del fin del mundo un medio para impresionar a sus vecinos e incitarles a que se conviertan. La situación cambia en el siglo XII que marca la aparición de anuncios de estado ideal que precederá al fin del mundo, se anuncia en la visión del advenimiento del ultimo emperador. El Apocalipsis del "Pseudo Metodio" redactado en el siglo VII en siriaco y traducido al griego. También se extiende después de los siglos X y XII la imagen de la Biblia Triburtina Latina, y desde el X el abad Adsón de Montier-en-Der en su obra De Ortu et Tempore Antichristi. Era un mensaje de paz y la esperanza de un período bienaventurado aunque no anunciaban transformaciones específicas ${ }^{15}$.

También en el XII se produce la transformación con el simbolismo alemán, que reflejaban una insatisfacción con la situación de la iglesia. Gerhoch de Reichersberg o la abadesa Hildegarda de Bingen. Esto llevaría a la aparición de Joaquín de Fiore que era crítico con la Iglesia y que anunciará violentas persecuciones para la cristiandad que llevará a la supresión de los males en la Iglesia contribuyendo al triunfo de la iglesia espiritual. Esto tuvo eco en los franciscanos en el siglo XIII. Después surgen los ideales rigoristas de San Francisco de Asís y después Juan Pedro Olivi y

15 Moore, Robert, La Première Révolution européene (X-XIII siècle,) Paris, Seuil, 2001. 
Ubertino de Casale. Esto siguió en el siglo en el XIV con otros franciscanos y otras profecías que abordan el problema de las tensiones sociales que reflejan la oleada de conflictos que agitan Europa en el siglo XIV

En relación al pensamiento medieval, y en consecuencia con lo anterior, es necesario distinguir dos posturas: por un lado, la ortodoxa (siguiendo a San Agustín, etc.) y, por otro lado, las heterodoxas (herejías), que a su vez tienen diferentes tipos, como los que hacen relación a la promesa de mil años de felicidad (milenarismo -principalmente Fiore) o los que predicen el advenimiento del juicio final. Joaquín de Fiore era crítico con la Iglesia y dirá que habrá violentas persecuciones para la cristiandad que llevará a la supresión de los males en la Iglesia contribuyendo al triunfo de la iglesia espiritual al final de la historia. Esto tuvo eco en los franciscanos en el siglo XIII. De aquí surgirán los ideales rigoristas de San Francisco de Asís y después Juan Pedro Olivi y Ubertino de Casale ${ }^{16}$.

San Agustín fue autor básico en la Edad Media, ya que sentó las bases de todo el pensamiento medieval, en lo que se refiere a la teología, la filosofía de la historia y la propia concepción institucional y jerárquica de la Iglesia. San Agustín en De civitate Dei se centró en el rechazo al milenarismo, que se basa en los siguientes puntos: 1) asimilación del Mundo y el orden del Mundo a la voluntad del Dios, y consecuentemente postulación de la bondad del Mundo, en contra de todas las tradiciones: gnóstica, maniquea..., que fueron el fundamento de muchos movimientos milenaristas; 2) defensa de la dignidad el cuerpo humano y crítica del ascetismo radical, que fue fundamental en muchos movimientos milenaristas y mesiánicos, como el priscilianismo o el donatismo, en época de San Agustín, y muchos otros en períodos posteriores. Para Agustín el cuerpo y su estructura es un reflejo del orden del Mundo y de la sabiduría divina. Por esta razón el ascetismo radical se puede interpretar como contestación política ${ }^{17}$; 3 ) defensa del orden político, en el paradigma de la Roma aeterna, desarrollado por San Agustín y su discípulo Orosio, paradigma sobre el que se asienta toda la teología política medieval, y en la que se basa la idea de Sacro Imperio Romano Germánico, a partir de Carlomagno. Esta identificación del orden político y el orden eclesiático es la que llevó a San Agustín a apelar al poder civil para reprimir la herejía donatista, creando así la teoría de la apelación al "brazo secular", que será fundamental en la Edad Media ${ }^{18}$.

${ }^{16}$ Rucquoi, Adeline, "No hay mal que por bien no venga. Joaquín de Fiore y las esperanzas milenaristas a fines de la Edad Media", Clio \& Crimen, 1, 2004, pp. 217-240.

17 P.Brown :El Cuerpo y la Sociedad, Paidós, Barcelona y Nicolas Trung y Jacques LeGoff, Una historia del cuerpo en la Edad Media, Barcelona, Paidós, 2005.

18 Ver Claude Carozzi, Apocalypse et salut dans le christianisme anciene et médiéval, Paris Aubier, 1999. 


\subsection{Tiempo, paz y Edad Media}

En la Europa de la alta Edad Media (VIII-IX) la idea de paz sirvió para buscar el reequilibrio político, la armonía social, la oposición al pillaje y la violencia, y hasta fue fundamental para el rearme espiritual. Así surgió la llamada "Paz del Rey", que fue un concepto jurídico de origen germánico surgido durante la Alta Edad Media y que se refirió en un primer momento a la protección jurídica de la persona del soberano. Por derivación, se extendió a los lugares que el monarca habitaba y los caminos que transitaba. Después fue usado para proteger mercados, ferias, personas, lugares. Esta paz regia dio lugar al concepto de paz territorial.

La Iglesia encabezó también importantes movimientos a favor de la paz, puesto que disfrutaba de habituales enfrentamientos con los señores feudales y se plasmaban en constantes episodios de rebelión, desobediencia y guerras, aunque hay que tener en cuenta que surgen en momentos de crisis y no cuestionan en lo esencial las fuentes del poder establecido

En este contexto se rescatan diferentes ideas de paz. Así surge la Paz de Dios (Pax Dei), que suponía limitar las acciones violentas contra los eclesiásticos y sus propiedades y también contra los pobres (después se extendió al resto de la población $)^{19}$. Esta protección se manifestaba en la solicitud de una especie de salvoconducto para todos los no combatientes y sus bienes. En Alemania se logró una cierta paz pública mientras que en el sur de Francia la autoridad de los reyes estaba en franca competencia con el poder de los señores feudales, por eso la "paz de Dios" tuvo éxito ahí. Todo esto quedó reflejado en las deliberaciones y términos de los debates sobre pactum pacis, constitution pacis, retauratio pacis et justiciae, pax reformanda, etc. de los concilios de Charroux-en-Poitou (989), Puy-en-Velay (990), Limoges (997) y Poiters (1000). Roberto el Piadoso la proclamó en Francia en 1010-1011 y contra los que violasen su juramento se previeron sanciones diversas.

También fue importante la Tregua de Dios, que limitaba en el tiempo la realización de actos violentos, impidiendo a los cristianos luchar durante ciertos día de la semana o durante ciertas fechas. Estas proposiciones tuvieron su primera expresión en Provenza pero se expandieron hacia otros lugares de Francia (Aquitania, Borgoña, Normandía, Besançon, etc.). Finalmente estos acontecimientos tuvieron su repercusión en el conjunto de poderes públicos, especialmente reyes y príncipes, al pasar de una paz personal y temporal hacia una paz territorial en la que se proclama triunfante el derecho público frente al derecho privado. En ese movimiento participaron no sólo autoridades eclesiásticas, sino también las autoridades políticas y los diferentes movimien-

19 Ver Dominique Barthélemy, L'an mil et la paix de dieu. La France chrétienne et féodale, Fayard, París, 1999 
tos sociales (hermandades, municipios), lo que nos indica la permeabilidad de esas ideas y su posible interacción en la toma de decisiones. Una manifestación práctica de todas cuestiones la representaron las agrupaciones de herejes: cátaros, husitas, valden$\operatorname{ses}^{20}$, que llevan al último término la interpretación de tregua y paz de Dios, porque se oponían a las formas de guerra, a matar a sus semejantes, e incluso a predicar la "no violencia" y el amor como eje central de la convivencia política. En el mismo sentido, está la creación de la promoción de caballeros de la paz y la creación de milicias de la paz, motivadas por la oposición a los señores feudales y contra los poderosos.

En todas estas manifestaciones, la paz aparece como un valor espiritual asociado a la equidad y a la justicia. La otra parte de todo esto es que no cuestiona las formas de violencia institucionalizadas o no, así como las guerras (defienden el término de "guerra justa"), la desigualdad económica, social, etc.

Además de todo esto también la paz estaba presente en los diferentes tratados y en las diferentes elaboraciones de planes de paz como el contenido en la obra de Pièrre Dubois (De Recuperatione Terre Sancte, 1306), Dante Aligheri (De Monarchia, 1310), Marsilio de Padua y Juan de Jandum (Defensor Pacis, 1324), etc.

A pesar de todo esto, los siglos XIII-XV están presididos por diferentes guerras en el Occidente Europeo. En cierta medida, la guerra fue causa y consecuencia de la crisis demográfica, agrícola y social, de las diferencias entre Señores feudales para ampliar su poder, y de las resistencias de campesinos y trabajadores urbanos, así como de la voluntad de extirpar las diferentes herejías mediante la fuerza y resistencia. La llegada de la peste a Europa a mediados del siglo XIV también contribuyó a todo ello ${ }^{21}$. De toda esta situación se concluyó que la guerra era beneficiosa para sus practicantes, como se puede comprobar en diferentes cronistas bajomedievales (Honoré Bouvet, Christine de Pisan o Geoffroy de Charny) ${ }^{22}$.

En este sentido, el año 1000 ha sido un año de grandes debates historiográficos sobre si su significado fue de gran cambio (Duby) o de continuidad (Barthélemy), una polémica que va asociada a toda una serie de terrores al fin del mundo y de la segunda llegada de Cristo, que traería la paz eterna ${ }^{23}$. Aunque no hay consenso,

20 Ver Baschet, Jérôme, La civilisation féodale. De l'an mil à la colonisation de l'Amérique, Flammarion, Paris, 2006, pp. 300-310.

21 Ver Biraben, Noël, Les Hommes et la Peste en France et dans les pays européens et méditerranéens, Paris-La Haye, Mouton, 2 vol., 1976.

${ }^{22}$ Ver Fernandez, Jon A., "Guerra y sociedad en europa occidental durante la Baja Edad Media (ss XIII-XV)", en AA.VV., La guerra en la historia, Universidad de Salamanca, Salamanca, 1999, pp.45-97.

${ }^{23}$ Sobre los terrores del año 1000, Georges Duby, L'an mil, Paris, Gallimard, 1980; Dominique Barthélemy, La mutation de l'an mil a-t-elle eu lieu?, Paris, Fayard, 1997; Sylvain Gouguenheim, Les Fausses Terreurs de l'an mil, Paris, Picard, 1999; y Robert Moore, La Première Révolution européene (X-XIII siècle), Paris, Seuil, 2001. 
unos autores apuestan porque el año 1000 fue un momento intenso, de gran violencia señorial y de convulsiones que llevaron a la mutación feudal, para otros sólo es un momento de tensiones sociales exageradas por la instauración de un nuevo orden feudal. Según otras interpretaciones, ni hubo mutación feudal ni escatología. Sea como fuera, el monje cluniacense Raoul Glaber habla de un mundo nuevo y lleno de optimismo.

El anticristo tiene una importancia fundamental en el imaginario medieval y a él se le asocian los cataclismos, etc. Los primeros cristianos fijaron en el año 500, aunque después fue "aplazado" al año 800, 970, 981, 992, 1065 y 1250. El abad Odón de Cluny estaba convencido de la venida del anticristo en el siglo XII, las primeras cruzadas se desarrollaron bajo la amenaza de un clima del fin del mundo. Durante el siglo XIII la preocupación por el Anticristo no ceja. En 1260 surgieron en Italia diferentes movimientos de penitentes y flagelantes. La peste negra de 1348 revivió la inquietud y suscitó un nuevo movimiento de flagelantes. También durante el gran cisma que dividió a la Iglesia entre 1378 y 1417 el Papa es calificado de Anticristo. Todo esto es visto por teóricos como Reinhart Koselleck quien afirma que es una estrategia para integrar la escatología en los tiempos presentes, como elemento de la estabilidad de la Iglesia y de su dominación.

En la misma línea y relacionado con esto surgieron toda una serie de movimientos apocalípticos, milenaristas y heréticos en los que tuvo gran influencia el Apocalipsis de San Juan, que tuvo en la cultura medieval un gran impacto tanto en la teología como en el arte. En esta oportunidad, el Apocalipsis no concierne sólo al fin del mundo sino al pasado, presente y futuro de la Iglesia y a un conjunto de movimientos sociales. Eso lleva a interpretaciones milenaristas (variantes de la escatología) que pronostican un futuro asociado a la fase última de la historia universal, aunque lejos de anunciar el fin de los tiempos y la destrucción del mundo prometen el preámbulo del reino de Cristo sobre la tierra, estableciendo para todos los hombres un orden paradisiaco de paz y de justicia. Aunque hay un gran debate al respecto, algunos tomando a San Agustín y a la La Cité de Dieu asocian el milenium a aquel momento histórico, mientras otras interpretaciones más literales de la Palabra sagrada incidían en un futuro que vendrá. San Agustín pensaba que la paz es un bien y no hay otro mas valioso y útil. Su idea fue "combatid sin violencia por la verdad" y con los herejes "combatid con la discusión y venced con la razón"

Otro de los autores clave en la idea de milenarismo fue Joaquín de Fiore, abad de un monasterio cisterciense de Calabria, y quien habla de la realización de una iglesia espiritual. Sus ideas tuvieron mucho éxito entre los franciscanos y los domi- 
nicos. Aunque el punto culminante del milenarismo medieval por su apoyo popular y por el empleo de la fuerza fue con la insurrección husita, movimiento encabezado por Jean Hus. El milenarismo permite la manifestación de la transformación social radical ${ }^{24}$ Claude Carozzi, Apocalypse et salut dans le christianisme anciene et médiéval, Paris, Aubier, 1999.

Sea como fuere, ambas teorías tienen un gran componente teleológico, puesto que buscan la paz como un fin y como un organizador externo de los propios acontecimientos históricos e historiográficos. La guerra y la paz en la Edad Media tienen un gran componente de fuerza y abuso. La violencia supone ejercer una fuerza moral o psicológica para imponer, coartar forzar o obligar, y la Iglesia la utilizó para lograr sus fines mediante construcciones teóricas con fuerte impacto social como el milenarismo, el apocaliptismo o la idea del fin del mundo.

\section{UNA APROXIMACIÓN A EL FIN DE LA HISTORIA EN LA ÉPOCA CONTEMPORÁNEA}

El fin de la Historia en la época contemporánea ha sido un tema recurrido en los últimos años ${ }^{25}$. La importancia de la historia de los acontecimientos, de la ideología y de las mentalidades, así como del estudio teórico e historiográfico de los diferentes fines de la historia contemporáneos hacen llegar a la conclusión de la necesidad de un replanteamiento del pensamiento teleológico basado en la consecución de una sociedad ideal tanto política como social, y en la necesidad de discutir conceptos como el presentismo, eurocentrismo, occidentalismo, dogmatismo, etc ${ }^{26}$. En definitiva, la necesidad de la puesta en marcha de una historia y una historiografía del tiempo actual como laboratorio para poder operar tanto con acontecimientos como con construcciones teóricas ${ }^{27}$.

Existen diferentes representaciones de fin de la historia en la época contemporánea: las liberales (Kojève, Fukuyama, Huntington) ${ }^{28}$, las postmodernas (Vatimo,

\footnotetext{
24 Ver Norman Cohn, Les Fanatiques de l'Apocalypse, Paris, Payot, 1983. Claude Carozzi, Apocalypse et salut dans le christianisme anciene et médiéval, Paris, Aubier, 1999.

25 Ver Sanmartín, Israel, Entre dos siglos: globalización y pensamiento único, Akal, Madrid, 2007 y ANDERSON, Perry, Los fines de la historia, Anagrama, Barcelona, 1996.

26 CATROGA, F., Caminhos do fim da História, Quarteto, Coimbra, 2003.

27 Ver Hartog, François, Régimes d'historicité. Présentisme et expériences du temps, Editions Seuil, Paris, 2003.

${ }^{28}$ FUKUYAMA, Francis, The end of History and the last man, The Free Press, New York, 1992.; KOJÈVE, A., Introduction à la lecture de Hegel, Gallimard, Paris, 1947; HUNTINGTON, Samuel P., El choque de civilizaciones y la reconfiguración del orden mundial, Paidós, Barcelona, 1997.
} 
Derrida, Baudrillard) ${ }^{29}$, las progresistas (Negri, Klein, George ${ }^{30}$ o las postocoloniales (Mignolo, Dussel) ${ }^{31}$. Todo en la idea de buscar una "sociedad perfecta" tanto en los social y lo político, lo intelecutal y lo mental.

En cierto sentido, el interés historiográfico por el presente es una de las señas de identidad de la historiografía actual. La investigación de los fines de la Historia es una reflexión del interés de los historiadores por la "historia de su tiempo", que es un rasgo constitutivo de la historiografia desde sus orígenes, cuestión en la que interviene su carácter de materia "pública", es decir, su capacidad para establecer o narrar memorias públicas del pasado, y sobre todo del pasado reciente

En cuanto a la idea de tiempo presente en la Edad Contemporánea o las "formas modernas" existe dos formas generales de representación ${ }^{32}$. Por un lado, la referida al tiempo que frisa el presente, a la llamada historia inmediata ${ }^{33}$, y a la historia del tiempo presente en su acepción más clásica que dependiendo del lugar se refiere bien a después de la Segunda Guerra Mundial (mundo francés), la transición democrática (en el caso de España) o los procesos dictatoriales (Río de la Plata) ${ }^{34}$. Todo esto supone una superación de toda una serie de limitaciones historiográficas que habían estado presentes en la historia contemporánea hasta la aparición de la llamada "nueva historia" 35 , cuando el historiador recupera su condición de sujeto

29 Ver CABRERA, Miguel A., "La historia y las teorías del fin de la historia", en BARROS, Carlos (ed.), Actas Congreso Internacional Historia a Debate, Santiago, 1995, pp. 209-222.

30 Klein, Naomi, La doctrina del shock : el auge del capitalismo del desastre, Barcelona : Paidós, 2007; Michael Hardt and Toni Negri, Empire, Harvard University Press, Harvard, 2000; François Houtart y Fraçois Polet (Coords), El otro Davos. Globalización de resistencias y de luchas, Editorial Popular, Madrid, 2001; George, Susan, Hijacking America : how the religious and secular right changed what Americans think, Cambridge, UK ; Malden, MA : Polity, 2008.

${ }^{31}$ Mignolo, Walter D., Local histories, global designs : coloniality, subaltern knowledges, and border thinking, Princeton : Princeton University Press, 2000; Mignolo, Walter D., La idea de América Latina : la herida colonial y la opción decolonial, Barcelona, Gedisa, 2007; Dussel, Enrique, Etica de la liberación en la edad de la globalización y la exclusión, Madrid, Trotta, 1998; Dussel, Enrique, Política de la liberación : historia mundial y crítica, Madrid, Trotta, D.L. 2007.

${ }^{32}$ Historia del tiempo presente : teoría y metodología, Cáceres, Universidad de Extremadura, Instituto de Ciencias de la Educación, D.L. 1998.

${ }^{33}$ Barros, Carlos, "Es posible una historia inmediata?", en http://www.h-debate.com/cbarros/ spanish/articulos/mentalidades/inmediata.htm, [consulta 13 de marzo de 2009]

Barros, Carlos, "El estatus epistemológico e historiográfico de la Historia Inmediata", http://www.h-debate.com/Spanish/presentaciones/lugares/montevideo3/audio.htm, [consulta 13 de marzo de 2009]

${ }^{34}$ Soto Gamboa, Ángel, "Historia del Presente: Estado de la cuestión y conceptualización", Historia Actual Online, №. 3, 2004.

35 Pérez Serrano, Julio, "La historia continúa", Historia Actual On Line, nº, 2003 en http://www. historia-actual.com/hao/pbhaoabs.asp?idi=ESP\&pgt=2\&pid=4\&pbl=HAO\&vol=1\&iss=1\&cont=1, [consulta 15 de marzo de 2009] 
en la investigación, especialmente con las codiciones internacionales de la posguerra y los cambios sociales e intelectuales materializados tras 1968, que es cuando se produjo una democratización tanto de la historiografía como del uso público del pasado y de las memorias en particular, algo que se ha acelerado en los años noventa con la globalizacion. Por tanto, sólo estamos en un proceso que comenzó desde los años sesenta y que es el de pareflexión sobre el "presente" en tanto problema histórico, que ha provocado una discusión a fondo de lo que es la "historia contemporánea" como período histórico y el nacimiento de una manera distinta de entender lo contemporáneo. Los fines de la Historia ayudan a mostrar una preocupación sobre el presente en la historiografía reciente tanto nacional como internacional, en el sentido de que no se puede presentar la historia del presente como una recuperación de la memoria histórica, o una historización de la memoria o a una historia de los imaginarios sociales. Su desarrollo guarda una estrecha relación con nuevos acontecimientos de los años 90 y el cambio de siglo así con su dimensión global. Para ello, es conveniente tener en cuenta las diferentes representaciones de la idea de la historia de presente en España ${ }^{36}$, (analizando las ideas avanzadas por los grupos de Almería, Cádiz, Extremadura, Madrid, La Rioja y Santiago de Compostela), en Alemania, en Francia (historia del tiempo presente e historia inmediata), en el mundo anglosajón (Contemporary history y la current history) ${ }^{37}$ y en América Latina (Argentina, Brasil, Uruguay), donde se utiliza el término de "historia reciente". El estudio de todas esas representaciones nos ofrece una utilización de las memorias y del presente. A su vez hay que considerar la sociabilidad relativa a nuevas formas de interacción, que ha surgido de esos grupos de trabajo en los que "inmediata", "nuestro tiempo", "tiempo presente", "contemporáneo" o "actual" pugnan por convencer a los investigadores y no tienen un significado idéntico pero sus diferencias no impiden reconocer la importancia del estudio de lo cercano $^{38}$.

Profundizando en lo mismo, sería erróneo presentar la historia del presente aislada del desarrollo de una historiografía del presente en la que se reúnen toda una serie de enfoques historiográficos que sólo se pueden estudiar en el contexto del desarrollo de la historia del presente, es decir, los Cultural Studies, la nueva histo-

\footnotetext{
36 Cuesta, Josefina, Historia del presente, Madrid : Eudema, D.L. 1993.

37 Ash, Timothy Garton, Historia del presente : ensayos, retratos y crónicas de la Europa de los 90, Barcelona : Tusquets, 2000

38 Actas del II, III y IV Simposio de Historia Actual, Logroño, Instituto de Estudios Riojanos, 1996, 1998, 2000 y 2004 y Actas I y II Congreso Internacional Historia a Debate, Santiago de Compostela, Santiago, 1995 y 2000.
} 
ria intelectual, los estudios postcoloniales. Pero no sólo eso, sino que metodológicamente las nuevas fuentes de información (Internet) y la nueva sociabilidad de lo historiadores alrededor de Internet han provocado el surgimiento de una suerte de estudios que podríamos llamar de historiografía del presente o inmediata en donde se une lo teórico, lo metodológico, lo histórico, lo periodístico y lo cultural. Por tanto, se acerca más a los acontecimientos recientes, a la historia inmediata, pero sobre todo reivindica una nueva actitud teórica frente a lo contemporáneo capaz de superar sus ambigüedades ${ }^{39}$.

\section{ENTRE LA ÉPOCA MEDIEVAL Y LA EDAD CONTEMPORÁNEA: LOS FINES DE LA HISTORIA POSTOCOLONIALES}

Los fines de la historia medievales y contemporáneos tienen una de las posibles conexiones en la idea de "larga edad media", que es un concepto desarrollado por Le Goff y desarrollado entre otros autores como Baschet, etc. Los historidores postcoloniales basan su tesis en la modernidad y en la importancia del renacimiento, aunque sea desde un punto de vista postmoderno ${ }^{40}$. El problema de algunos de estos autores es que no consideran la historiografía relativa al tema. Veamos algunas consideraciones interesantes al respecto ${ }^{41}$. Mignolo habla de la colonización del tiempo, ya presupuesta en el siglo XV. El renacimiento europeo se autodefine por su modernidad y para definir como tal necesita colonizar el tiempo e inventar una edad media que lo antecede y lo separa de la edad antigua ${ }^{42}$. Según Dussel, America Latina fue la primera periferia de Europa, ya que la Ilustración hizo que España no jugara un papel en su formación.

Está claro que las periodizaciones históricas son convenciones artificiales. Aunque hay consenso cuando empieza la Edad Media, que sería en 476 con la caída de Roma. Por su parte, el fin estaría situado en 1492, y es dividida en baja Edad Media (V-X), Plena Edad Media (XI-XIII) y Alta Edad Media (XIV y XV).

39 Ver Barros, Carlos, "El estatus epistemológico e historiográfico de la Historia Inmediata", http://www.h-debate.com/Spanish/presentaciones/lugares/montevideo3/audio.htm, [consulta 13 de marzo de 2009]

40 Ver Walter Mignolo, The Darker Side of the Renaissance, Literacy, Territoriality and Colonization, University of Michigan Press, Ann Arbor, 1995.

41 Fruto de lo expuesto es deuda de mis conversaciones en París con Jérôme Baschet, quien me ha puesto en la pista de mucha bibliografía sobre el particular.

42 Ver Walter D. Mignolo, Historias locales/diseños globales. Colonialidad, conocimientos subalternos y pensamiento fronterizo, p. 40. 
Pese a todo esto, el Renacimiento no supone la ruptura absoluta, decisiva, que quiso ser: existe una "larga Edad Media", que se extendió hasta el fin del siglo XVIII, incluso se puede decir que este período concluyó con la Revolución Francesa y la Revolución Industrial ${ }^{43}$. La Larga Edad Media es un período de elaboración y construcción del mundo moderno. La Edad Media expresa un conjunto de valores que se deshace entre 1750 y 1850 . Vamos a exponer, pues, una periodización que rompe con la clásica distinción entre lo medieval y el renacimiento. Le Goff propone esa "Larga edad media". Según esta idea, habría una serie de estructuras fundamentales persistentes en la sociedad europea entre el siglo IV y el XIX. Así novedades que son consideradas en el Renacimiento habrían tenido su inicio en los siglos XI-XIII como la imprenta, reformas, fundación de las ciencias modernas, Galileo, Descartes y Newton tendrían su sustento en la Edad Media. Con esto se rompe con el convencionalismo según el cual la Edad Media representó una época histórica oscura y permite revisar el concepto de la modernidad sujeta a los tiempos del Renacimiento. La idea de modernidad, en principio, es consustancial a la idea de Renacimiento, pero lejos de marcar el fin de la Edad Media, el renacimiento (los renacimientos) son un fenómeno característico de un largo periodo medieval ${ }^{44}$.

Tradicionalmente la Edad Media es considerada como un mundo opuesto a la modernidad: mundo de la tradición/modernidad; mundo rural/industrialización, Iglesia/mundo laico; fragmentación feudal/unidad moderna. Pero esas transformaciones no son del Renacimiento si no del siglo $\mathrm{XIX}^{45}$. En otro sentido, Mignolo obvia el desarrollo histórico de que los colonizadores que llegaron a América estaban desplazando la Edad Media y sus instituciones a la nueva realidad geográfica, con lo que no podemos hablar de Renacimiento, que sería un concepto totalmente occidental en América ${ }^{46}$. Por otro lado, hay una evidente relación entre la Europa Feudal y la llamada América colonial. La encomienda no tiene características feudales, pero muchas de sus limitaciones son fruto de la dialéctica feudal; por su parte las haciendas sí tienen relación con la dominación feudal. También hay similitudes entre la iglesia colonial y la iglesia feudal: grandes tierras de posesión, estructura interna del clero, rol de órdenes mendicantes, doctrina y ritual, formas de evange-

\footnotetext{
43 Jacques Le Goff, Una larga Edad Media, Paidós, Barcelona, 2008, p.25.

44 Ver Jacques Le Goff, "Pour un long Moyen Âge" en L'Imaginaire médiéval, Gallimard, Paris, 1985.

45 Ver Jérôme Baschet, La civilisation Féodale. De L'an mil á la colonisation de l'Amérique, Flammarion, París, pp. 29-44.

${ }^{46}$ Ha habido un fértil debate entre diferentes autores sobre el feudalismo en América Latina, como Gunder Frank, Ruggiero Romano, Marcello Carmagnani, etc.
} 
lización, predicación y confesión. También hay paralelismos con la organización espacial de las villas, con lo que debemos de hablar de un feudalismo tardío y dependiente ${ }^{47}$.

Las tesis postcoloniales tienen una "cara b" un tanto desagradable, puesto que es en exceso postmoderna, conservadora, identitaria y tramposa. Además, pasa por alto el estudio de la historia y de la historiografía latinoamericanas.

Para empezar, existe una relación intensa entre postmodernismo/colonialidad. Concebir la colonialidad independientemente de las concepciones eurocéntricas es un error, puesto que no se pueden separar ya que ninguna idea(s) se hallan en estado puro. Mignolo piensa en una "pureza de ideas" que no existe. Las ideas, como las interpretaciones, evolucionan en contacto con la historia, la política y la teoría, y sus diferentes concepciones. Según Mignolo la idea de América Latina es una invención Europea moderna limitada en la visión que los europeos tenían del mundo y de su propia historia. La transformación en la geopolítica del conocimiento comenzó con el reconocimiento de que incluso la defensa postmoderna de la pluralidad de interpretaciones no merece celebrarse en tanto se restrinja a una diversidad de interpretaciones enmarcadas en el conocimiento eurocentrico, moldeado por la teología y la egología. Así, los acontecimientos que condujeron al surgimiento de la ida de America favorecieron la aparición del pensamiento fronterizo, que es el pensamiento intercultural.

En otro sentido, en las tesis postocoloniales ser reduce la llamada "leyenda negra" española a una cuestión de lucha entre imperios, sin percatarse que un estudio de esa situación le llevaría a entender mejor el concepto Europeo sobre lo latino y lo hispano. Mignolo parece obviar en sus consideraciones y concepciones que España y Portugal empezaron a pertener a la "periferia" occidental muy pronto. Para Mignolo la "leyenda negra" de la corrupción española iniciada por los británicos para demonizar al Imperio Español como estratagema para dominar la economía del Atlántico en el siglo XVII era parte de una lucha europea por las riquezas económicas, políticas e intelectuales del Nuevo Mundo. Allí se origina la diferencia imperial que se extendería a lo largo del siglo XVIII y forjaría la concepción de América Latina ${ }^{48}$.

La obsesión colonial de Mignolo le lleva a argumentar que hay cuatro ideologías siguiendo en parte a Wallerstein: conservadurismo, liberalismo, socialismo y

\footnotetext{
47 Ver Jérôme Baschet, La civilisation Féodale. De L'an mil á la colonisation de l'Amérique, Flammarion, París, pp. 380-416.

${ }^{48}$ Walter Mignolo, La idea de América Latina. La herida colonial y la opción decolonial, Gedisa, Barcelona, 2007, p. 79.
} 
colonialismo. Para él, el colonialismo nadie lo quiere promover y todos le quieren poner fin, "se habla de civilización, desarrollo, democracia pero nunca de colonización”, dice. El colonialismo se apodera del presente y del pasado de los oprimidos (Fanon). En algún libro, Mignolo argumenta incluso el cristianismo como ideología ${ }^{49}$. Nada hay que objetar a esa clasificación, sólo decir que el colonialismo está presente en todas y cada una de ellas: conservadurismo, liberalismo y socialismo, como está presente el imperialismo, el machismo, etc. Es curioso que no se refiere nunca al nacionalismo como ideología.

En la misma línea, hay una fijación con la civilización como sujeto histórico, teórico e historiográfico. Intelectuales criollos del XIX como Domingo Faustino Sarmiento utilizaron el paradigma civilización versus naturaleza para describir a la élite criolla en contraposición a la barbarie de los indígenas. Después las élites criollas se autocolonizaron, al adoptar la noción francesa de "latinos" como forma de oponerse a lo anglo que representaba la civilización.

Mignolo explica que mientras que la civilización europea se dividió en culturas nacionales, la población del resto del mundo tenía cultura pero no civilización. Los latinos de América del Sur tenían una cultura pero no civilización. Los latinos tenia una cultura moldeada en parte por los ideólogos francesas de la latinidad, pero no eran civilizados. Eso llevó a que los latinoamericanos fuesen considerados europeos de segunda clase que carecían de ciencia y de la compleja historia de Europa. La civilización no es más que una descripción que los europeos hacen de su propio papel en la historia, una civilización genocida y bárbara. Se pliega a las civilizaciones de Huntington, al que cita como referencia en la materia y en base al que hace las consideraciones sobre este particular. En diferentes pasajes alude a la tesis de "el choque de las civilizaciones" y también a las tesis supuestamente racistas de Huntington hacia los hispanos en el libro Quienes somos. Asimismo, Mignolo se muestra molesto porque Hungtington considera a America Latina como una civilización diferente a la Occidental y sí a Australia, Nueva Zelanda, etc. Pero, ¿qué interés tiene lo que considere Huntington?.

También hay una creencia en la Teoría de la dependencia como algo positivo por el mero hecho de ser "propiamente latino", sin considerar causas y consecuencias. Las ideas son evaluables más allá de donde se piensan, aunque es importante el contexto de creación y los círculos referenciales político, histórico e historiográfico. En el caso de Mignolo, sostiene que en la Teoría de la dependencia distintas interpretaciones implican que existe un principio compartido de conocimiento y de

49 Walter D. Mignolo, Historias locales/diseños globales. Colonialidad, conocimientos subalternos y pensamiento fronterizo, Akal, Madrid, 2003 
reglas del juego, mientras que admitir que hay diferentes perspectivas significa que los principios de conocimiento y las reglas del juego tienen una posición geohistórica que funciona dentro de la estructura de poder del mundo colonial moderna. Para entender cómo funciona, según Mignolo, es necesario contar con una Teoría de la Dependencia para el dominio epistemológico, que ofrece la explicación del diferencial de poder y económico. La historiografía oficial y dominante es cómplice de la modernidad o de la postmodernidad que permiten perpetuar el mito de la modernidad como algo separado de la colonialidad.

Asimismo, se desarrolla la "idea" de América Latina "frente" y no "en parale1o" a Europa y EE.UU. Para Mignolo el proyecto de América Latina no puede ser viable y si lo fuese debería de se un proyecto de oposición frente a Eruopa y EE:UU. Él prefiere el desarrollo de la llamada "Unión sudamericana" y avanzar hacia una "epistemología del sur" que es parte del FSM y el desarrollo de proyectos como el Mercosur (Argentina, Brasil, Paraguay, Uruguay, Bolivia y Chile) frente al NAFTA (México, EE.UU y Canadá).

La insistencia en el concepto de raza. Mignolo en una pirueta intelectual poco clara equipara "raza" a "etnia" 50 , cuando una es descriptiva y la otra cultural; una estática y otra dinámica, y que se va modelando con la historia, la cultura, etc. En cierto sentido, Mignolo hace una traslación equivocada de principios a la identidad. Siguiendo a Fanon, habla no de la lucha de clases sino de razas (negra) ${ }^{51}$. Mignolo hace teorización racial cuando debería de centrarse más en valores, conceptos, ideas, etc.

Otra de las características es la ligereza al hablar del concepto de nación. Mignolo aborda el término "nación" con gran infantilidad y más pensando en una clave identitaria que política, histórica y teórica. Mignolo observa que la nación reemplazó a la religión y entonces surgió un tipo de comunidad imaginaria en la que la noción de cultura pasa a ser cultura nacional. Evidentemente Mignolo obvia cómo se constituye una nación y cuáles son los elementos que comparten la misma. Por otro lado, no sabe que las naciones se han forjado a lo largo de siglos y que es algo que va variando puesto que está sujeto al devenir histórico y al día a día ${ }^{52}$.

Cambiando de tercio, se puede observar una confusión en la definición de historia, y entender ésta como algo ligado a la díada modernidad/postmodernidad. Mignolo piensa que la historia debe ser entendida como una heterogeneidad histórico-estructural y no una sucesión lineal de acontecimientos. Según él, si

50 Walter Mignolo, La idea de América Latina. La herida colonial y la opción decolonial, p. 41.

51 Walter Mignolo, La idea de América Latina. La herida colonial y la opción decolonial, p. 177.

52 Walter Mignolo, La idea de América Latina. La herida colonial y la opción decolonial, p. 42. 
hacemos lo primero damos cancha a la perspectiva de historias locales en lugar de grandes relatos y se abre un espacio donde tienen cabida diferentes puntos de vista y procesos históricos. Mignolo ofrece una gran confusión en estos términos puesto que la historia no tiene por qué no tener en cuenta a las historias locales, y por contra no tiene porque ser lineal ni teleológica. Parece que hereda una definición de la historia postomoderna que no le deja definir los conceptos y las ideas en las que quiere presentar la historia que pretende desarrollar.

Otra de las cosas a destacar, es la incapacidad para entender que es posible el desarrollo de una historia mundial, porque lo asocia al proyecto moderno desde una perspectiva postmoderna. Mignolo piensa que una historia mundial o universal es una tarea imposible. A su parecer, durante los últimos quinientos las historias universales se han insertado en diseños globales. Las historias locales se ven abocadas a enfrentarse al colonialismo moderno y se asientan en el lugar anteriormente que ocupara la historia mundial ${ }^{53}$. Para Mignolo la única historia posible es la suma de historias locales, sin percatarse de que lo que supone la historia mundial es simplemente una pluralidad y complejidad que lleve a diferentes perspectivas, enfoques y métodos.

Por último, Mignolo ofrece una tesis geoepistémica postmoderna, pero en el peor sentido de conservadora y referenciada a modelos equivocados (Huntington, etc.).

\section{CONCLUSIONES}

En el estudio de la historiografía del presente existe la posibilidad de ceñirse a la cuestión de la representación del tiempo medieval a través del concepto de "Larga Edad Media", que estudia la pervivencia del mundo medieval europeo en el "nuevo mundo" y que, a su vez, supone un gran punto de ruptura para las tesis postocoloniales, en las que trataremos también su relación y diálogo con el neoconservadurismo estadounidense.

Existe una cierta relación entre los diferentes fines de la Historia: del fin de la Historia en la Edad Media y Contemporánea a la postocolonial, pasaríamos a la parte más delicada del trabajo que sería buscar tanto la comparación como sus relaciones, puesto que mucho de lo que tiene el fin de la historia en la Edad Media está contenido en los diferentes fines de la historia contemporánea (teleologismo, idea

53 Walter Mignolo, La idea de América Latina. La herida colonial y la opción decolonial, pp. 81-82. 
lineal de progreso, etc.). Por tanto, comparación y relaciones/orígenes son las bases para desarrollar una cierta genealogía de la idea de "fin de la historia"

También es evidente que la comparación entre las dos épocas se centra en las diferentes coyunturas históricas alrededor del milenarismo, es decir, año mil frente a año dos mil, pero no sólo en lo relativo a la cuestión de fin de siglo (en discusión para la Edad Media), sino en torno a la cuestión mental y de representaciones intelectuales (no es un secreto que parte del éxito de Fukuyama es su asociación con este aspecto).

En definitiva, los fines de la Historia en la Edad Media con un amplio abanico de utillaje historiográfico, metodológico e histórico. Conviene recordar que la cuestión de los fines de la Historia en la Edad Media es una cuestión estudiada por diferentes autores en vertientes muy diferentes. Por ejemplo, George Duby o Jean Delumeau con un enfoque de historia de las mentalidades; Henri Focillon desde una perspectiva más de historia política; Francis Rapp desde una óptica de historia de la religiosidad; así como Etienne Gilson para la filosofía de la Edad Media; o los trabajos sobre las herejías de Ozment o M. D. Lambert; sobre el anticristo $^{54 ;}$ y sobre el fin del mundo ${ }^{55}$. Estos casos, y muchos otros, abordan la cuestión del fin de la historia desde ópticas definidas, pero no en su conjunto, aunque recientemente empiezan a aparecer trabajos más complejos ${ }^{56}$, que es la forma que se debe adoptar para hacer una reflexión real sobre el tiempo de la Edad Media y su relación con la idea de los fines de la historia.

54 Bernad McGinn, El anticristo. Dos Milenios de fascinación humana por el mal, Paidós, Barcelona, 1994 o René Girard, Veo a Santán caer como el relámpago, Anagrama, Barcelona, 2002

55 Guillermo Fatás, El fin del Mundo. Apocalipsis y melino, Marcial Pons, Madrid, 2001

56 Michael Frassetto, The Year 1000: Religious and Social Response to the Turning of the First Millennium o el de Frederic J. Baumgartner Longing for the End. A History of Millennialism in Wester Civilization, palgrave, New York, 2001 o Dominique Barthélamy L'an mil et la paix de Dieu, Librairie Arthème Fayard, 1999. 